whether valine, cysteine and phenylacetic acid are biochemical precursors of penicillin" is not true in the light of the work by Dr. Arnstein and his collaborators.

In spite of these minor criticisms, the book is well laid out and well printed. Workers in the field of synthetic drugs will sympathize with the authors' problem of how to deal with the many trivial names of a single drug. Though perhaps not bringing the reader quite as up to date with the subject as he might wish, this book will, nevertheless, prove invaluable as a reference work to those interested in the chemistry and activity of synthetic drugs.

F. R. BATCHELOR
The editor himself contributes an authoritative review of the influence of the constituents of the medium on the biosynthesis of penicillin, and pays a well-deserved tribute to Dr. Bisset for his "lucid and beautifully illustrated article" on the saprophytic Actinomycotes. Finally, an article on microbiological assay not only surveys the common laboratory techniques but also includes a section on statistical analysis, showing clearly the influence of this approach in the actual operation of the assay laboratory. The standard set by this volume, and the list of topics mentioned for review in forthcoming volumes, should ensure a wide and continuing interest in the series.

N. Blakebrovgh

\title{
MICROBES ON THE MOVE
}

\author{
Biochemical Engineering \\ Unit Processes in Fermentation. Edited by Dr. R. \\ Steel. Pp. 328. (London: Heywood and Co., Ltd., \\ 1958.) 50s. net.
}

Progress in Industrial Microbiology

Vol. 1. Edited by Dr. D. J. D. Hockenhull. Pp. viii +248. (London : Heywood and Co., Ltd., 1959.) 50s. net.

GINCE the advent of the commercial production of $S$ antibiotics in the 1940 's, the application of microorganisms to industrial purposes has been given a new stimulus, which has more than compensated for the declining importance of fermentation processes for the production of such materials as alcohol, acetone and butanol under the impact of the petrochemicals industry.

These two publications represent the first attempt in Great Britain to collect within a reasonable compass some of the vast store of information in this field. As such they will be welcomed by all whose pre-occupation with a particular aspect limits their view of the horizon.

Steel's book is based on a series of lectures given in Manchester in 1957 by a panel of speakers, who, for the most part, have considerable experience in research or in the industrial applications of microbiology. Its scope is limited essentially to the fermentation industries, which cover only part of the activities of the biochemical or biological engineer. This is clearly seen by comparing the coverage of this volume with the topics mentioned in the introductory chapter on "The Scope of Biochemical Engineering"'. Only one chapter is contributed by chemical engineers practising in this field, and this is concerned largely with mechanical engineering design. Its title is, therefore, a misnomer. Nevertheless, it provides an introduction to a field in which chemical engineers are likely to be increasingly involved. Indeed, its very limitations should act as a stimulus to a more forthright chemical engineering approach. The book will also serve to give those entering this field some notion of the problems and approach of the biochemist and biologist, and of the multifarious activities of the ubiquitous microbe.

The second book, from the same publisher, is the first volume in what promises to be a valuable series. The topics chosen represent a good balance between the more academic approach of the 'pure' microbiologist and biochemist on one hand, and the needs of microbiological technology on the other. The balance is maintained in the chapters on the tetracyclines, microbial fat and riboflavin synthesis.

\section{Periodic Law}

By D. I. Mendeleieff. Edited by B. M. Kedrov. Pp. 830 (Russian text). (Moscow: Acad. Sci. U.S.S.R., 1958.) $33 \mathrm{r}$.

THIS valuable and substantial volume containing Mendeleieff's publications relative to the Periodic Law represents a publication quite independent from Mendeleieff's "Scientific Archives" reviewed in these columns in 1955 (Nature, 176, 965; 1955), the first volume of which was published in 1953, while the second and the third volumes remain as yet unpublished. The present volume belongs to the series "Classics of Science" and is apparently entirely due to the initiative and labour of B. M. Kedrov, assisted by the late T. N. Chentzova.

The first section of the book contains reprints of fifteen "Principal Articles" by Mendeleieff relating to the Periodic Law. Actually the first item of this collection is not an article at all but a copy of the first issue of the Periodic Table (March I, 1869). Besides this copy the book contains a large number of photographic and printed reproductions of different variants of the Periodic Table.

The second item in this collection is the first article of Mendeleieff dealing with the Periodic Law published in the Journal of the Russian Chemical Society $(1$, pp. $60-77 ; 1869)$. This is followed by a number of shorter articles and then by the Russian text of the German article entitled "Die periodische Gesetzmäs. sigkeit der chemischen Elemente" published in Liebigs Annalen, 1871, Supp. VIII, Heft 2, pp. 133229. Extracts from this article were published by W. Crooks in the quarterly Journal of Science, No. 55, (1877), and a full translation in the Chemical Neus, 40 (1879), and 41 (1880). According to Mendeleieff himself, this article presented "the best summary of my views and arguments on the periodicity of the elements and was the main text used for the numerous comments on this system. This article was the main cause of my renown as a scientist". Short papers on peroxides follow with others on the atomic weight of yttrium, the cerium group of metals, gallium and the rare metals. Number thirteen is the Russian text of the Faraday Lecture entitled "The Periodic Law of the Chemical Elements". The lecture was delivered by Mendeleieff on May 23/June 4, 1889, before the Chemical Society in London ( $J$. Chem. Soc., 55, $634 ; 1889)$. The remaining items are an articlo from the Russian Encyclopædia of 1898, and an extract from the "Principles of Chemistry", 1906 edition.

The section entitled "Additions" contains a miscellaneous collection of Mendeleieff's articles of lesser 